\title{
MODIFICANDO A ATUAÇÃO DOCENTE UTILIZANDO A COLABORAÇÃO
}

\author{
Lilia Maria Marques Siqueira* \\ Paulo Roberto Alcântara**
}

\section{Reumo}

Este artigo descreve a necessidade de se inovar a prática pedagógica em salas de aula com base principalmente no uso da metodologia tradicional, predominante no ensino de disciplinas de graduação. Focaliza a aprendizagem colaborativa como uma alternativa metodológica centrada no aprendiz para se modificar a atuação docente. Apresenta algumas possibilidades de atuação colaborativa na educação superior, alguns dos princípios educacionais da colaboração e como novos ambientes de ensino-aprendizagem se diferenciam daqueles utilizados no passado.

Palavras-chave: Aprendizagem colaborativa, Educação superior, Prática docente.

\section{Abstract}

This article describes the need to innovate the pedagogical practice in classrooms mostly based in the traditional methodology, which is a predominant method in the undergraduate teaching disciplines. It focuses on the collaborative learning as a learner-centered methodological alternative to modifying the teaching practice. It presents some possibilities of collaborative role in higher education, some educational principles of collaboration and how new teaching-leaming environments differ from those of the past.

Keywords: Collaborative learning, Higher education, Teaching practice.

\section{Introdução}

Para apresentar uma proposta de inovação metodológica, cabe analisar a atuação docente no presente momento. Em muitos cursos de graduação

* Mestranda do Programa de Mestrado em Educação da PUCPR e Professora do Curso de Engenharia Elétrica da PUCPR. Travessa Lange, n. ${ }^{\circ} 277$, ap ${ }^{\text {to }}$ 701, Batel, Curitiba - PR, CEP 80240-170.

E-mail: lilia@rla01.pucpr.br

* Ph.D. em Educação e Desenvolvimento Humano pelo George Peabody College of Vanderbilt University e Professor do Programa de Mestrado em Educação da PUCPR. Rua: Santo Inácio de Loyola, n. ${ }^{\circ}$ 97, Guabirotuba, Curitiba - PR, CEP 81520-250. E-mail: alcantpr@rla01.pucpr.br 
ainda predomina o estilo de aula baseado na concepção tradicional, na qual o aluno é basicamente o ouvinte, atento ao professor falante, que se apresenta como detentor do conhecimento. Nessa modalidade, há pouco espaço para a troca de idéias sobre o conteúdo abordado e não há incentivo à interação entre os colegas.

Atualmente, educadores têm debatido sobre a necessidade de se ampliar a atuação pedagógica, alterando metodologias de ensino e ambientes de aprendizagem, para atender às constantes mudanças da realidade. As propostas de ação pedagógica requerem uma profunda reflexão do professor, que necessita aproximar-se do aluno, para incorporar ao seu modelo de atuação elementos significativos para o aluno, garantindo a sua adesão ao programa. O planejamento das aulas e as estratégias decorrentes devem ser delineados considerando-se os anseios do aluno e de que forma ele realiza a interação com o conhecimento elaborado, para permitir um ganho na aprendizagem em relação ao modelo precedente. Se, eventualmente, o docente não possuir uma preparação ou educação formal para atuar como professor do ensino superior, pode acontecer desse professor valorizar demasiadamente a técnica, relegando a mediação professor-aluno-conhecimento a um segundo plano. Este comportamento poderá estar associado à educação que recebeu na sua graduação, quando o aluno pouco se dirigia ao professor e realizava seus estudos de forma individual. Na aprendizagem colaborativa, a proposta é utilizar a interação existente entre os alunos e os temas de estudo, tornando o contato com o conteúdo mais dinâmico e observado. Com a mediação do professor, os alunos poderão avançar na análise crítica do conhecimento existente, exercitando a comunicação escrita ou oral, na direção da construção de novos conhecimentos.

\section{Aprendizagem colaborativa como proposta de atuação docente}

Os autores que discutem e aplicam a colaboração citam as contribuições da teoria de Vygotsky como uma sustentação teórica para a aprendizagem colaborativa. Vygotsky nos remete à extrema responsabilidade do professor em sala de aula, que pela rotina cotidiana pode acabar ficando encoberta: 0 aluno só aprende se for submetido a situações de aprendizagem. Ele expõe que uma criança, apesar de possuir um organismo perfeito e de coordenar movimentos de braços e cabeça, só aprenderá a escrever, por exemplo, se estiver submetida a situações de aprendizagem da escrita. Ampla é a missão do docente, que não pode prescindir em oferecer uma oportunidade de aprendizagem para 0 aluno que está pronto para dela fazer uso e construir novos conhecimentos. 
Com base na teoria de Vygostky, acrescenta Oliveira (1996, p. 56):

Do mesmo modo que o desenvolvimento não é um processo espontâneo de maturação, a aprendizagem não é fruto apenas de uma interação entre 0 indivíduo e o meio. A relação que se dá na aprendizagem é essencial para a própria definição desse processo, que nunca ocorre no indivíduo isolado.

E, mais adiante, "é um processo de ensino-aprendizagem, que inclui aquele que aprende, aquele que ensina e a relação entre essas duas pessoas" (OLIVEIRA,1996, p.56). Também Anastasiou (1998, p.194) chama esse processo de "ensinagem", para permanecer o esclarecimento de que a existência de um ensino implica necessariamente na ocorrência da aprendizagem. Se a um processo de ensino não houver a correspondente aprendizagem, cabe ao educador avaliar onde falhou o ensino e posteriormente reverter, reelaborar sua ação em sala de aula. A proposta da colaboração concretiza uma possibilidade de responder ao exposto por Anastasiou (1998):

Para que este processo (de ensinagem) se efetive não basta, como já foi dito anteriormente, o dizer do professor em sala de aula: há que se possibilitar intencionalmente - um novo processo metodológico que considere a abordagem do conhecimento como resultante da realidade, portanto, tomandoa como ponto de partida e de chegada, passando pelo processo de construção do pensamento com e do aluno. (p.195, grifo nosso)

Considerando o desenvolvimento intelectual dos alunos ingressantes no ensino superior, podemos inserir atividades com maior grau de autonomia e responsabilidade, para favorecer a apresentação de conceitos. Esses conceitos podem ser apresentados acrescentando-se que sofreram reformulações de acordo com o novo significado a ele atribuído ou à sua aplicação na realidade. Dessa forma, o conteúdo adquire uma historicidade, uma finalidade e não apenas se configura em um item a mais para se estudar.

Outro aspecto se faz necessário reforçar: para que se utilize a colaboração, é necessário que o professor reconheça que existe o conhecimento, formal, elaborado e o conhecimento informal, sem protocolos, estabelecido pelas relações interpessoais. No acesso ao conhecimento elaborado, se o aluno deseja verificar se houve aprendizagem, essa avaliação se dará por intermédio de outro indivíduo, presente naquele momento com o aluno, ou representado pelas suas obras (i.e., livros, textos, artigos). Ainda que aparentemente restrito ao conhecimento formal quando, por exemplo, o aluno resolve um exercício de física, ao consultar as respostas aos exercícios propostos pelo professor indica que ele está mediando o que aprendeu com outro indivíduo, nesse caso, simbolizado pelo autor do livro que forneceu a resolução. 
Um tipo de aplicação da aprendizagem colaborativa é o grupo do consenso, ou seja, utilizar o conhecimento formal para confrontá-lo com a realidade ou a situação problema e construir novo conhecimento a partir do debate, da troca de idéias entre os pares.

Bruffee (1999) diferencia as duas formas de educação como: alicerçada e não alicerçada: "a educação alicerçada assume que o conhecimento é algo que fornecemos às pessoas. Os professores ajudam os alunos a assimilar, absorver ou sintetizar conhecimento... Em contraste, a educação não alicerçada assume que a educação é uma reaculturação." (p.295)

\section{A influência da cultura}

Como o termo aculturação significa adotar as características culturais ou padrões sociais de uma determinada cultura, o termo reaculturation, introduzido por Bruffee, refere-se a uma passagem para outra cultura, para outro ambiente que possua outras normas, valores diferenciados daquele que nos encontramos. A cultura está presente no planejamento de aulas; o que se deve aprender é, em parte, determinado culturalmente, de acordo com os valores e normas da coletividade em que a instituição está inserida, com o grau de desenvolvimento tecnológico daquela sociedade e das suas principais necessidades. Como se deve ensinar também sofre a influência cultural e as metodologias de aprendizagem devem considerar os aspectos da vida em sociedade dos seus alunos.

O ingresso ao ensino superior é uma transição cultural de grande porte, equivalente à primeira vez que fomos à escola. $\mathrm{O}$ universo acadêmico é distinto do ensino fundamental e as expectativas dos pais e professores também o são. Raramente, entretanto, o professor explica claramente aos alunos que acabaram de ingressar em uma comunidade que essa possui diferente modo de agir, e de se expressar, e que o docente pode ser visto como um agente que irá auxiliá-los nessa tarefa de adaptação.

A idéia defendida por Bruffee (1999, p.9): "a educação universitária é essencialmente reaculturação, e a reaculturação essencialmente colaborativa", convida-nos a uma reflexão sobre a ação docente em sala de aula e favorece a aproximação entre aluno e professor. A influência que os alunos exercem uns aos outros pode ser direcionada para incrementar a aprendizagem. É necessário esclarecer aos alunos ingressantes na universidade que estão em processo de transição, adentrando a uma comunidade que possui diferentes valores, princípios e objetivos educacionais daquela que pertenciam anteriormente. Dessa forma, pode ser alcançada uma meta comum em que alunos necessitam transpor essa fronteira e o professor atua como mediador, buscan- 
do estratégias de aprendizagem que possibilitem uma adaptação do indivíduo ao seu novo ambiente escolar.

Acrescente-se aqui a influência cultural do próprio docente, ao planejar o seu fazer em sala de aula, conforme citado por Linhares (1995):

O próprio professor, ainda que não tenha, ele próprio, organizado o conhecimento, pela pesquisa, pode e deve, ao ensinar, permear o processo e a matéria com a história viva, articulada por ele próprio como sujeito, ensinando os alunos a refazê-la e apreendê-la como sujeitos - coletivos e individuais - definidos pela sua responsabilidade, pelos seus interesses e seus desejos. (p.184)

A ênfase do professor em determinado assunto, a maneira de trazer esse conteúdo para a discussão em sala de aula, a definição de prioridades, estão impregnadas da subjetividade do docente, fruto da educação que 0 formou, que por sua vez possuía características culturais e temporais bem definidas. Tornar claro essa passagem para o aluno, sem criar o estereótipo de que "isso está ultrapassado", auxiliará a acalentar o sentido histórico do surgimento e da pertinência dos saberes e permitirá uma postura mais responsável no processo de maturação das habilidades de análise e síntese.

\section{Possibilidades de a tuação de forma colaborativa}

Embora o ambiente da sala de aula não seja o único, é sem dúvida o ambiente mais comum que se dispõe para o encontro com os alunos. Precisamos reverter o ambiente austero da disposição das carteiras, em frente à mesa do professor, que reforça a autoridade da sala de aula como exclusiva do docente. Facilmente se transforma a sala de aula em ambiente colaborativo, mediante o reposicionamento das carteiras, proposição de atividades em equipe e fornecimento de material bibliográfico. Como um grupo de profissionais trabalhando para oferecer uma solução técnica para um cliente, os grupos pesquisam fontes bibliográficas e trazem-nas para a apreciação dos demais componentes da equipe, visando a um consenso, subsidiado pela teoria e pela interação. Eventuais impasses podem ser mediados pelo professor, desfavorecendo a competição, para que a atividade não deixe de cumprir sua finalidade.

Outra possibilidade é utilizar os laboratórios de informática, que possuem a simpatia dos alunos e contam com a interação assíncrona, utilizando a ferramenta Fórum de algum programa computacional, ou na falta desse, listas de discussão formadas em páginas do curso, preparadas pelos alunos e professores e disponibilizadas aos participantes em um provedor comercial de 
acesso de todos. Entretanto, se for proposta uma pesquisa na Internet sobre determinado tema polêmico, como por exemplo, os efeitos da radiação eletromagnética das antenas de estação rádio-base do sistema móvel celular e aos alunos fosse solicitado um debate por meio de um fórum, a pesquisa bibliográfica seria atualizada, superando a simples cópia.

Há uma necessidade crescente de se superar o papel unicamente auxiliar do computador no ensino. O compartilhamento da rede pelos computadores de uma universidade e a facilidade de acesso de qualquer ponto, permitiu superar a visão auxiliar do computador como, por exemplo, correio eletrônico. Ao utilizar a ferramenta Fórum, disponível em aplicativos colaborativos como o ambiente EUREKA, WebCT, entre outros, todas as contribuições dos alunos ficam registradas e disponíveis a todos os participantes, promovendo um debate fora da sala de aula.

Collins (1991) analisou o papel da tecnologia de computadores no ensino-aprendizagem observando escolas que se reestruturaram e que começaram a usar tecnologia em seus currículos. Identificou que os novos ambientes de ensino-aprendizagem ocasionaram mudanças expressivas no comportamento das salas de aula, levando-as: (a) do ensino da sala inteira para 0 ensino em pequenos grupos; (b) de aulas expositivas para aulas de acompanhamento; (c) do trabalho com os melhores estudantes para o trabalho com os mais fracos; (d) de estudantes passivos para estudantes mais engajados; (e) da avaliação baseada em testes para avaliação baseada em produtos, progresso e esforço; (f) de estruturas sociais competitivas para estruturas sociais cooperativas; $(\mathrm{g})$ de todos os estudantes aprendendo as mesmas coisas para estudantes aprendendo coisas diferentes; e (h) de uma aprendizagem predominantemente verbal para uma integração do raciocínio visual e verbal.

Alcântara (1999) apresenta alguns cuidados que devem ser tomados ao se inserirem atividades no laboratório de informática:

Professores devem proporcionar um contexto significativo para a tecnologia de computadores, eliciar e discutir conhecimento anterior com estudantes, ensinar estratégias significativas, desafiar estudantes e fornecer encorajamento durante atividades que utilizam tecnologias de computadores. (p.115)

Sem interferir no processo de amadurecimento das idéias dentro do grupo, o docente deve estar atento a eventuais impasses ou desvios das discussões para o lado pessoal, constantemente oferecendo apoio e suporte ao bom andamento das atividades.

As bibliotecas, utilizando-se as salas reservadas para trabalhos em grupo, efetivam-se como um dos ambientes mais adequados para se desenvolver as qualidades requeridas na colaboração e que serão exigidas na vida profissional: grupos de pessoas não escolhidas, reunidas para investigar um problema, com acesso aos dados necessários, debatendo e construindo uma 
solução conjunta, minimizando ou até mesmo eliminando a competição individual.

Um ambiente que conta com a adesão dos alunos é o laboratório de experimentos, pois, pela natureza das atividades realizadas, permite aliar as condições favoráveis do ambiente e sua relação direta com a natureza dos fenômenos estudados. Por meio da experimentação, os alunos verificam a aplicabilidade dos conceitos e realizam as conexões com os conceitos estudados, minimizando a dicotomia teoria-prática. Com o amadurecimento dessas atividades, poderão os alunos evoluir para situações em que não mais necessitem recorrer ao laboratório, estabelecendo as relações mesmo antes da verificação experimental.

\section{Incentivando a comunicação para trabalhar de forma colaborativa}

Por mais que o docente tenha consciência da importância de inovar a prática pedagógica, a simples inserção da colaboração dificilmente alcançará bons resultados sem o devido preparo dos alunos. Como já foi dito anteriormente, o ingresso ao ensino superior compreende uma transição cultural de muitos aspectos, entre eles o como aprender.

Muitos alunos estudam de forma pouco produtiva e se distraem ao mínimo descuido, reforçando a sua concepção de que "estudar é cansativo". No papel de agente de transição cultural, cabe ao docente desenvolver as habilidades de trabalhar em grupo, para que o aluno possa contribuir para 0 grupo e para o seu próprio desenvolvimento.

Masetto (2002) relatou, como resultado de sua pesquisa com alunos da PUCSP, que:

As pesquisas salientam as estratégias incentivadoras da interação do grupo como facilitadoras da aprendizagem. Os depoimentos de alunos falando das estratégias integradoras do grupo e estimuladoras da participação, apresentando seus depoimentos a respeito do clima da sala de aula que favorece a aprendizagem, testemunhando como aprenderam a partir do grupo classe ou do contato com os colegas, sinalizaram para a importância da vivência com os outros em sala de aula.

A comunicação na aprendizagem colaborativa possui uma importância fundamental. $\mathrm{O}$ professor deve estar atento às manifestações entre os alunos de um grupo e entre os grupos, valendo-se de instrumentos de registro para assegurar-se que os reais objetivos da atividade estão sendo atingidos. $\mathrm{O}$ docente necessita incentivar a participação coerente, certificar-se de que há 
uma distribuição de autoridade, enfatizar a responsabilidade de cada um pelo aprendizado do colega, limitar o debate aos argumentos, sem permitir que seja desviado para o nível pessoal, assegurar que existam oportunidades iguais de manifestar o desenvolvimento da habilidade comunicativa. Durante o desenrolar da atividade, observar atentamente esses aspectos dentro de cada grupo, e na apresentação final dos trabalhos, averiguar como os grupos reagem frente às diferentes soluções encontradas.

Vygotsky (2000) sintetiza a importância da verbalização para que se possa expressar o que pensamos:

A comunicação entre duas mentes é impossível, não só fisicamente como também psicologicamente. A comunicação só pode ocorrer de forma indireta. O pensamento tem que passar primeiro pelos significados e depois pelas palavras. (p.186)

É adequado ressaltar que a comunicação não necessariamente deve ser presencial, podendo ser utilizadas as ferramentas de discussão, ou listas eletrônicas, como a experiência de Overbaugh (2002), que propôs aos alunos questões que geravam controvérsia, deveriam se manifestar por meio de um e-mail que ficava disponível a todos os participantes. Posteriormente, outros alunos poderiam concordar ou discordar daquele posicionamento, gerando uma discussão assíncrona. Overbaugh (2002) encontra amparo em seu procedimento didático no Cognition and Technology Group at Vanderbilt University (CTGV), que descreve duas mudanças primordiais em educação:

(1) o conhecimento é ativamente construído por indivíduos através da interação com seu ambiente e através da reorganização de suas próprias estruturas mentais, e (2) o reconhecimento da importância do contexto social para a aprendizagem. Ferramentas de comunicação assíncronas mediadas por computador, não somente promovem pensamento reflexivo e crítico, mas também permitem a ocorrência de uma aprendizagem mais profunda e significativa. (p.117)

Em qualquer um dos ambientes de aprendizagem, ao término da atividade, como complemento à avaliação, deve ocorrer a expressão da síntese, organizada pelo pensamento, que poderá ser exposta por uma apresentação oral para o grupo, ou por textos, painéis, ou mesmo por programas de computador dedicados a uma função educativa específica.

\section{Considerações finais}

Conforme comentado anteriormente, para melhor compreender onde reside a base da colaboração, é necessário: 
- conceituar a existência de dois tipos de conhecimento: o conhecimento não alicerçado ou construído por meio da interação entre colegas, e o conhecimento alicerçado ou formal;

- visualizar a universidade como uma comunidade na qual os indivíduos que dela desejam tomar parte realizarão uma transição cultural, da escola cuja comunidade faziam parte anteriormente, para a comunidade acadêmica;

- reconhecer que a transição cultural (reacculturation) para a educação superior se dará mais rapidamente e com maior qualidade se for realizada coletivamente;

- utilizar a influência entre os pares, entre os colegas, na direção da aprendizagem; o docente auxiliando a desenvolver nos alunos as habilidades de respeito mútuo, cooperação e responsabilidade perante o grupo;

- enfatizar a necessidade da boa comunicação entre os colegas, enfatizando a precisão de linguagem, e a utilização correta dos conceitos e definições, já que a construção do conhecimento não alicerçado se dá por meio da mediação entre os indivíduos;

- preparar os alunos para atuarem de forma colaborativa, incentivando a autonomia e desencorajando a competição.

Ressaltamos a proposta de inserção da aprendizagem colaborativa como uma alternativa metodológica e aspectos pertinentes para ponderar quanto à sua aplicação nas universidades. Evidentemente, diversos cursos estão procurando estratégias para incentivar a aprendizagem, enquanto outros já utilizaram a colaboração, usando ou não tecnologias, e obtiveram resultados positivos.

Middlecamp (2003) destaca um depoimento de alunos que trabalharam de forma colaborativa em aulas de química, na Universidade de Wisconsin: "trabalhar em grupos permite perguntar aos outros membros do grupo ao invés de descobrir tudo por si próprio." As aulas de química utilizando os grupos de colegas permitiram a troca de idéias entre os membros do grupo auxiliando a dissipar dúvidas que impediriam a realização da atividade.

Freeman (2003) também propôs estudo colaborativo para Cálculo, permitindo aos alunos escolherem seus colegas, formando grupos de três, informando aos alunos antes do início das atividades o que iriam fazer e por que, trabalhando por um curto espaço de tempo e gradualmente expandindo, ressaltando comportamentos de grupo: ouvir, permanecer na carteira, participar, conferir o entendimento de cada um dos colegas. 
Behrens (2000) relata a sua experiência:

Os projetos de aprendizagem possibilitam a produção do conhecimento significativo. Os alunos que se envolvem nesses processos de parceria têm a oportunidade de desenvolver competências, habilidades e aptidões que serão úteis a vida toda. $\mathrm{O}$ foco da ação docente passa do ensinar para 0 aprender e, por conseqüência, focaliza o aluno como sujeito crítico e reflexivo no processo de "aprender a aprender", propiciando-lhe situações de busca, de investigação, autonomia, espírito crítico, vivência de parcerias, qualidades exigidas para os profissionais do século XXI. (p.128)

Uma outra experiência colaborativa é o estudo relatado por Behrens, Alcântara e Viens (2001), denominado Projeto PACTO (Pesquisa em Aprendizagem Colaborativa com TecnOlogias Interativas) que teve como objeto de pesquisa a busca por estratégias de ensino-aprendizagem baseada na colaboração que utilizassem a tecnologia como ferramenta para possibilitar a produção do conhecimento e que modificassem tanto a ação docente do professor como sua postura com os alunos do curso de Arquitetura no programa de aprendizagem Sistemas Estruturais. Além disso, o projeto buscou também envolver os alunos participantes com seus pares e professor. Alcântara, Behrens e Carvalho (2001) apresentaram um depoimento em vídeo digital relatado por quatro alunos encontrado no CD-ROM do Projeto PACTO que retrata bem a mudança de atuação docente e que diz o seguinte:

(G.) Não só na matéria de sistemas, mas em todas as matérias consideradas difíceis. Eu acho que você tem, eu particularmente tenho medo de estar olhando aquela matéria e não estar assimilando muita coisa ali, ou melhor, estar assimilando, mas muita coisa eu não estou entendendo do que eu estou assimilando. Aí, eu olho para o lado e meu colega está copiando. Você está entendendo? Não, não estou. Aí, você olha para o resto da turma. Aí, dá aquela agonia, sabe! Eu acho que no convívio desta matéria, do jeito novo, você tem um contato muito maior com os seus colegas. Porque numa sala de aula corriqueira você conversa com seu colega, às vezes nem está conversando sobre a matéria e não passa disso, acabou a aula o professor fecha seu livinho e vai embora, e você também, fala até amanhã e pronto. Já numa aula de dependência, do jeito que está, via Internet. Ah! Olhe só, viu o que saiu na Internet, o professor $\mathrm{R}$. mandou e-mail pra mim, nós vamos ter que fazer esse exercício, vamos lá na casa do C. comer uma pizza e aí a gente faz o exercício. Não tem nada a ver com aula, é verdade, aconteceu isso, eu estou falando porque aconteceu.

(F.) Mudou tudo, mudou a forma da gente ver a matéria, mudou o gosto que a gente tem pela matéria e a forma do professor com a gente. Agora ele virou amigo nosso. 
(C.) Eu não tinha falado com o professor ano passado. Tinha aula com ele, ia toda a semana e nunca tinha falado com ele, acho que nem cumprimentava ele. E agora eu falo com ele normalmente.

(F.) Ele era sério, entrava lá, dava a matéria e ia embora. E uma vez a gente tentou falar com ele pra mudar o dia da prova, não teve jeito. Ai, que professor é esse, inacessível e ficou por aí. E poxa, agora o cara se revelou um ótimo professor, está nos dando tudo.

(R.) Se você procurar ele, com certeza você vai ter uma resposta.

A mudança de postura do docente diante do aluno, com uma visão ampliada da educação superior, que supera o mero cumprimento do conteúdo, contribui para o aperfeiçoamento da docência. Ampliando a conscientização de que $o$ aluno ingressa na universidade com diversas capacidades intelectuais já desenvolvidas, e que servem como base para o planejamento e a aplicação de novas situações de aprendizagem, adequadas ao grau de complexidade do assunto, o docente percebe que sua atuação em classe pode assumir papel decisivo no desenvolvimento de outras habilidades necessárias e aspiradas pelo aluno.

Por essas razões, acreditamos e as pesquisas em aprendizagem colaborativa Goodsell, Maher, \& Tinto (1992); Johnson, Johnson, \& Smith (1986); JOHNSON, Johnson, \& Smith (1991); Kadel \& Keehner (1994); Smith (1986); Springer, Stanne \& Donovan (1997) mostram ser possível melhorar o ambiente em sala de aula; a participação dos alunos; a confiança desses em seu potencial de construção; e o desenvolvimento das habilidades de crítica, autonomia e interdependência. Devido à aproximação intensa do ensino com as necessidades da sociedade, os ganhos para os alunos ultrapassam a mera aprovação no programa. Gradativamente, estaremos contribuindo para ir além da formação do profissional, restituindo para a sociedade um cidadão consciente, atuante e transformador.

\section{Referências}

ALCÂNTARA, Paulo R. Tecnologia multimídia na educação regular e especial. Revista Educação e Tecnologia, Curitiba, ano 2, n. 4, p. 111-131, 1999.

ALCANTARA, Paulo R; BEHRENS, Marilda A.; CARVALHO, Ronaldo G. CDROM do Projeto PACTO: Pesquisa em aprendizagem colaborativa com tecnologias interativas (1999-2000). Curitiba, PR: Pontifícia Universidade Católica do Paraná, 2001. 
ANASTASIOU, Lea G. C. Metodologia do ensino superior. Curitiba: IBPEX Autores Associados, 1998.

BEHRENS, Marilda A. Projetos de aprendizagem colaborativa num paradigma emergente. In: NOVAS Tecnologias e Mediação Pedagógica. Campinas: Papirus, 2000.

BEHRENS, Marilda A.; ALCANTARA, Paulo R.; VIENS, Jacques. Projeto PACTO (1999-2000): Implementação de uma metodologia inovadora no ensino superior na PUCPR. Colabora: Revista Digital da Cva Ricesu, Santos, v. 1, n. 2, p. 20-56, 2001. Disponível em: http:// www.ricesu.com.br/colabora/n2/index1.htm Acessado em 13.09.2002.

BRUFFEE, Kenneth A. Collaborative learning. Higher education, interdependence, and the authority of knowledge. 2nd ed. . Baltimore: Johns Hopkins, 1999.

COLINS, A. The role of computer technology in restructuring schools. Phi Delta Kappa, v. 73, n. 1, p. 28-36, 1991.

FREEMAN, Mike. Teaching stories: MathExcel: Calculus among friends. National Institute for Science Education (NISE), University of Wisconsin-Madison. Disponível em: http://www.wcer.wisc.edu/nise/cl1/cl/story/freemanm/ TSMFA.htm Acessado em: 14.04.2003.

GOODSELL, A., MAHER, M., \& TINTO, V. Collaborative learning: A sourcebook for higher education. University Park, PA: National Center on Postsecondary Teaching, Learning, \& Assessment, 1992.

JOHNSON, D. W., JOHNSON, R. T., \& SMITH, K. A. Academic conflict among students: Controversy and learning. In: R. S. Feldman (Ed.). The social psychology of education: Current research and theory. Cambridge: Cambridge University Press, 1986. p. 199-231.

JOHNSO N, D. W., JOHNSON, R. T., \& SMITH, K. A. Active learning: Cooperation in the college classroom. Edina, MN: Interaction, 1991.

KADEL, S., \& KEEHNER, J. A. Collaborative learning: A sourcebook for higher education. In: Parsley, K. (Ed.). ____._. University Park, PA: National Center on Postsecondary Teaching, Learning, \& Assessment, 1994. v. 2.

LINHARES, Célia F.S. Política do conhecimento e conhecimento da política na escola: perspectivas para a formação de professores. Educação e Sociedade, n. 50, p.170-190, Abr. 1995.

MASETTO, Marcos. Curso para formação de professores da FEI. Disponí- 
vel em: http://www.escoladavida.eng.br/anotacaopu/masetto_1.htm Acessado em 23.04.2002.

MIDDLECAMP, Cathy. Teaching stories: Students speak out on collaborative learning. National Institute for Science Education (NISE), University of WisconsinMadison. Disponível em: http://www.wcer.wisc.edu/nise/cl1/cl/story/middlecc/ TSCMA.htm Acessado em: 14.04.2003.

OLIVEIRA, Marta Khol. Pensar a educação: contribuições de Vygotsky. In: Piaget; Vygotsky. Novas contribuições para o debate. 3 ed. São Paulo: Àtica, 1996.

OVERBAUGH, Richard. Undergraduate education majors' discourse on an electronic mailing list. Journal of Research on Technology in Education. Eugene, OR, v.35, n. 1, p.117-138, Fall, 2002.

SMTH, K. A. Cooperative leaming groups. In S. F. Schomberg (Ed.). Strategies for active teaching and learning in university classrooms. Minneapolis, MN: University of Minnesota, 1986. p. 18-26.

SPRINGER, Leonard, STANNE, Mary Elizabeth, \& DONOVAN, Samuel. Effects of cooperative learning on academic achievement among undergraduates in science, mathematics, engineering, and technology: A meta-analysis (Unpublished Report). Madison, WI: University of WisconsinMadison and National Center for Improving Science Education, The National Institute for Science Education, April 1997.

VYGOTSKY, Lev. Pensamento e linguagem. São Paulo: Martins Fontes, 2000 . 